\title{
Leadership Education and Sustainable Development: Guidelines for Updating the Curriculum
}

\author{
Denise Fortier ${ }^{1}$, Nicolas Viens ${ }^{1}$
}

\begin{abstract}
The sustainable business movement is likely the most important environmental movement in the world today. Therefore, universities must create an education system that does not destroy the biosphere. More specifically, given that businesses are powerful institutions, leadership and sustainable development (SD) should be an integral part of the business curriculum. The current lack of educational content on SD is linked to several issues. First, we need to approach leadership education from a sustaincentric paradigm, thereby moving away from emphasizing profitability at the expense of a healthy ecological, social, and economic context. Second, there remains a paucity of theoretical and practical tools for educating leaders to take on the SD challenge. Indeed, there is confusion regarding how leadership relates to successful implementation of environmental sustainability. In this paper, we outline some guidelines for leadership and SD. Accordingly, we acknowledge the fundamental complexity of SD and question the potential for contributions from biomimicry. We join the call for combining voices from multidisciplinary perspectives, including the physical and social sciences, as a necessary first step in our quest to take on the SD challenge and conclude that leaders must integrate a form of 'shared leadership' where followers are empowered to improve ecological innovation and find "green" alternatives.
\end{abstract}

Keywords: Leadership Education, Leadership and Sustainable Development

\section{Introduction}

Our global ecosystem cannot support the infinite growth that guides current organizational strategy. The sustainable business movement may be the most important environmental movement in the world today (Schein, 2015). However, despite the fact that higher education institutions can be effective communication channels for sustainability issues (Lertpratchya, Besley, Takahashi, Zwickle \& Whitley, 2017), universities are still teaching a system that is destroying the biosphere (Schein, 2015). Educators need to cultivate a more holistic curriculum for sustainability leadership and train future organizational leaders to look for improved ways to cope with current exigencies and make the necessary changes for environmental sustainability (Lertpratchya et al., 2017; Schein, 2015; Stubbs \& Cocklin, 2008). More specifically, for students to effectively learn about sustainability, educators need to tackle leadership education from sustainable worldviews and provide leaders with tools to carry out sustainable actions.

Perhaps the continued lack of sustainability in leadership education is directly related to confusion regarding how leadership relates to successful implementation of environmental sustainability (Metcalf \& Benn, 2013). In this paper, we argue for leadership education within a sustaincentric mindset, and seek to identify guidelines for 
leadership and sustainable development (SD) to guide curriculum development.

On an epistemological level, perhaps the scarcity of potential leadership theory for SD stems from a lack of theoretical grounding to enable a sustainable future (Gladwin, Kennelly \& Kraus, 1995). So far, research has been implicitly conducted from a mindset where the ultimate goal has been profit maximization and where consumption is seen as a proxy for quality of life (Schein, 2015; Stubbs \& Cocklin, 2008). In other words, our research, and ultimately our approach in the classroom, has been conducted from a technocentric or neoclassical paradigm.

As we look for SD guidelines, we find different points of views outlined in the literature with regards to what content should be taught in business schools. While some argue that we need to replicate the successes of the traditional technocentric paradigm and only address corresponding failures for a sustainable future (Hanna, 1995), others are adamant that we must move away from this paradigm and turn to a worldview grounded in the belief that all human values depend on a healthy ecological, social, and economic context. While we encourage students to reflect upon- and ultimately critique- the main worldviews and their corresponding assumptions related to SD, we side with researchers and practitioners who claim that we must train future leaders to work within a sustaincentrism paradigm, one that holds the potential to lead us down a sustainable path (Gladwin et al., 1995).

Once we agree to proceed within the parameters of sustaincentrism, another challenge with identifying guidelines for sustainable leadership is rooted in the fundamental complexity of the concept of SD. This creates a canvas where leaders are navigating within a sea of icebergs (Schein, 2015). Clearly, finding answers necessitates an acknowledgement of the depth and scope of the SD problem, another issue to be addressed in business school.

Finally, a major hurdle holding us back with integrating SD in the curriculum is our lack of understanding regarding the leadership tools required to bring on the necessary changes. Indeed, some proponents of SD expect our leaders themselves to take us into a sustainable future (Delios, 2005; Metcalf \& Benn, 2013; Uhl-Bien, Marion \& McKelvey, 2007). As such, it has been argued that leadership for sustainability requires leaders of extraordinary abilities (Metcalf \& Benn, 2013). But is it realistic to place the burden mainly on leaders alone?

Some believe that we could learn valuable lessons from the field of biomimicry. They argue that, by tapping into the knowledge embodied by nature's time-tested patterns and strategies, we can identify biomimetic solutions that can be applied to solve technical and social challenges (Benyus, 2002; Roome, 2001). However, for leaders to be able to integrate biomimetic-inspired solutions, the latter would need to clearly evidence a transfer of functional or organizational principle from biology, a goal that would only be possible if the analogy between the natural and the leadership models is not lost in translation (Kennedy, Fecheyr-Lippens, Hsiung, Niewiarowski, \& Kolodziej, 2015). Empirical evidence is not yet available so that the parallel between these fields of study can in fact be made.

Still, it seems unlikely that, on their own, leaders will have sufficient information to grasp the scope of the SD problems and develop the needed solutions (Uhl-Bien et al., 2007). Perhaps our best bet with regards to leadership and SD will be to combine multiple 
voices from different disciplines in the problem identification and problem solving phases (Allenby, 2011; Hodgman, 2017, Schein, 2015).

As well, leaders can tap into a valuable pool of ideas for enhanced SD within their own organizations. Indeed, it appears warranted to involve employees from multiple levels in the organization in these collaborative efforts, with the added potential to attract better candidates, motivate them to excel, and retain them longer due to higher happiness levels (Hodgman, 2017). Our educational challenge then becomes to train future leaders to be open to multidisciplinary ideas and to listen to- and motivate- their workforce to participate in SD efforts.

If we heed the call for a form of 'shared leadership' as a necessity to SD (Metcalf \& Benn, 2013) and combine it with a multidisciplinary approach to understanding sustainability problems, we can improve how we educate leaders so they potentially delve deeper into the complexity of issues, do justice to their scope, and successfully take on SD challenges.

\section{Literature Review}

There is increased recognition that topics related to sustainability must be included in the business school curriculum (Stubbs \& Cocklin, 2008). In fact, students have shown an environmental awakening linked to college and graduate school years, a period that significantly contributes to the formation of an ecological worldview (Schein, 2015). Thus, if we seek to orient students towards worldviews and careers linked to SD we need to introduce these topics in university so future leaders can understand the assumptions that underlie interpretations of sustainability in business contexts (Schein, 2015; Stubbs \& Cocklin, 2008).

So far, no cohesive theory of sustainability leadership has reached either the academic or the corporate mainstream literature (Schein, 2015). While trying to identify the root of the problem regarding the lack of theory and practice on SD, part of the blame can be attributed to the academic discourse on strategic management, one that has neglected issues related to the biosphere, to environmental quality, to the ecosystem, and ultimately to sustainable development (Gladwin et al., 1995), not to mention the resistance to change built into academic institutions. Instead of disassociating humankind from the natural world, we should instead seek to understand these as interdependent systems (Gladwin et al. 1995). In other words, the economic system that provides humans with material goods should be acknowledged as grounded in an ecological system. This is true for educators and leaders alike.

The reality is that technocentrism, also known as the neoclassical economic paradigm (Stubbs \& Cocklin, 2008; Wielkiewicz \& Stelzner, 2005), remains the dominant worldview guiding business theory and practice, where humans are seen as not only separate from nature but also as superior to it, and thus as having the right to master nature for their own benefit. According to this perspective, the earth's resources are considered virtually limitless (Gladwin et al., 1995). In short, this perspective relies on free markets where increased production and consumption of goods and services feed unlimited economic growth (Stubbs \& Cocklin, 2008). More specifically, the creation of wealth is the sole purpose of organizations operating within this mindset and thus wealth 
creation should not be limited in any way (Delios, 2005). This mindset has been at the root of course content in business schools.

The technocentric neoclassical lens that has guided the evolution of business research and education has blessed us with impressive advances and riches on many dimensions over the last two centuries. However, these forces were carried out on a widespread scale- and at an accelerated rate- at the expense of depleting resources (Benyus, 2002). In other words, the organizational metaphor we have been teaching our students has been reduced to human-only exchanges within and across organizations has therefore restricted their conceptualization; this has lead us down an unsustainable path (Gladwin et al., 1995).

Some don't fault the technocentric mindset itself for our current anthropocentric society but instead point the finger at individualistic greed and the faulty ownership rights of natural resources along with a lack of appropriate accounting for resource use (Hanna, 1995). According to this perspective, all that is needed for SD would be to integrate environmental concerns with ongoing business practices. Within a functional decisionmaking paradigm, we could work towards synergy with profits and productivity while reducing environmental risks (Hanna, 1995).

Others take a more radical stance, rejecting the possibility of infinite growth in a finite environment from a less anthropocentric worldview. Embraced by those who consider the earth as the mother of life, where humans are just one component of the system, proponents of ecocentrism believe nature has intrinsic value, independent of human values and consciousness (Gladwin et al., 1995; Stubbs \& Cocklin, 2008). Situated at the opposite end of the dichotomy from technocentrism, and having evolved mainly in opposition to it, ecocentrism places limits on what humans can and cannot do but also fails to embrace the capacity of human intellect or the omnipresence of technology.

Ecocentrism therefore appears to be stuck in the past, for instance arguing for optimal population sizes that we cannot go back to. Thus it has been concluded that the technocentric and ecocentric worldviews are mainly self-defeating counter-forces (Gladwin et al. 1995). As such, neither worldview holds the capacity to generate the required answers to a sustainable future. Though we agree that these topics should be discussed within business courses thereby enabling students to reflect on and critique these epistemological assumptions, we encourage educators to push the discussion further and argue for leadership grounded in a sustainable paradigm.

\section{Working within a Sustainable Paradigm for Leadership Education}

Moving forward with leadership and SD requires scholars to work within a paradigm that offers a greater balance between economy, ecology, and social dimensions, also known as the triple bottom-line approach grounded in people, profit, planet. More specifically, our quest for SD asks that we not only connect organizations to the sources of life in which they operate, we should do so by reconciling the technocentric and ecocentric worldviews, and move forward with a more holistic approach. A sustainable way forward might therefore be grounded in sustaincentrism. Based on the premise that humans are part of the biosphere in organic and ecological terms, and are above the biosphere in intellectual terms, sustaincentrism- a worldview also advocated for by the 
ecological modernizers- confirms that all human values depend on a healthy ecological, social, and economic context (Gladwin et al., 1995; Stubbs \& Cocklin, 2008). Sustaincentrism not only places humans above the biosphere in intellectual terms but it also encourages precautions and humility in the face of complexity in ecological and human systems (Gladwin et al., 1995).

\section{Beating Inertia with Collaboration}

Moving forward based on the premise of sustaincentrism, the responsibility in achieving ecological sustainability falls squarely on the organizations (Shrivastava, 1995). Even though consumers and government are also key players in the fight for ecological sustainable development, organizations must first be reformed, redesigned, restructured to minimize their negative ecological impacts (Shrivastava, 1995). Clearly, organizations cannot continue to dissociate themselves from providing quality of life to the members of the communities in which they operate; in order to only benefit a few of these people. As a rule, most organizations are not interested in changing consumption patterns, nor do they believe they have the capabilities to do so. After all, their vested interests, financial realities, and organizational inertia prevent radical restructuring (Shrivastava, 1995; Wielkiewicz \& Stelzner, 2010). Clearly there is a need for better measures of economic welfare that systematically incorporate ecological costs (Shrivastava, 1995).

However, if businesses are the only institutions powerful enough to foster necessary changes for sustainability, the latter must become a source of competitive advantage (Gladwin et al., 1995). As educators, we must move away from the belief that leaders must strive for either profit or sustainability and that organizations must sacrifice profit if they seek to gain sustainability (De Luca, 2012b).

Delios (2005) believes that the responsibility to develop SD practices falls to the organizational leaders who will be called upon to identify ways in which they can implement SD initiatives without jeopardizing their ability to remain competitive. Indeed, the intensity of competitive markets, especially in this age of globalization, can make SD initiatives risky at best. Unfortunately, conventional leadership models simple do not provide the tools to create the necessary radical transformation (De Luca, 2012b). Due to the significant costs related to SD and the nature of highly competitive markets in most industries, it is argued that leaders' potential contribution to SD can only take place in collaboration with policy makers. By working together to better serve the needs of employees and external stakeholders, leaders and policy makers can find ways to change the formal and informal regulations and practices that define the nature of competition (Delios, 2005).

In short, we must make the business case for SD, from energy savings, product innovation, increased market share and employee engagement and train future leaders to work collaboratively with policy makers (Delios, 2005; Schein, 2015).

\section{Leadership Lessons from Biomimicry}

Biomimicry, a field of study that stems from the natural sciences and that has gained momentum in recent years, points to the centrality of nature while also embracing 
the capacity of the human intellect in the fight for sustainability (Benyus, 2002).

According to the biomimicry mindset, the role of nature is threefold. First it serves as a model that offers designs from which humans should take inspirations. Second, nature is a measure of what works, what is appropriate, and what lasts. And third, nature acts as a mentor, providing valuable insights for humans to learn from (Benyus, 2002). Indeed, research in the natural sciences now point to findings that enable us to see nature's patterns more clearly, a realization that has propelled the start of the nature-based innovations. Indeed, many scientists, architects, designers, and engineers around the world have turned to nature as model, measure, and mentor to come up with design solutions that are innovative and sustainable (De Luca 2012a,b).

With biomimicry, the aim is to derive principles from biology and use those principles as stimulus for ideation (Kennedy et al., 2015). Accordingly, by tapping into the knowledge embodied by nature's time-tested patterns and strategies, we can potentially identify biomimetic solutions that can be applied to solve technical and social challenges (Benyus, 2002).

A proponent of biomimicry, De Luca (2012b) argues that we need a radical new vision, a radical transformation where we apply ecological thinking to achieve an era of sustainability. She claims that radically different ways of interacting, communicating, collaborating, and co-creating with each other are necessary.

Though we hope to eventually be able to integrate lessons from biomimicry, we need further research so we can transfer functional or organizational principles from biology to the field of leadership and SD. Only once we can confirm that the analogy between the natural and the corresponding leadership models is not lost in translation can we integrate such knowledge in our leadership practices (Kennedy et al., 2015). At this time, empirical evidence is not yet available to confirm the parallel between these fields of study. All the same, it is likely that our business curriculum would benefit from exploring nature-inspired patterns of SD and from the spirit of collaboration and co-creation inspired by biomimicry.

\section{Leading within the Complexity of Sustainable Development}

Organizations are only able to foresee and adapt to environmental conditions if they are based on the strategic decisions of their leaders (Starik \& Rands, 1995). So while trying to understand how leadership relates to successful implementation of environmental sustainability, it might behoove us to acknowledge the multiple levels of complexity associated to leadership and SD. Not only are organizations themselves complex adaptive systems, these operate within wider complex adaptive systems of social responsibility and environmental sustainability (Metcalf \& Benn, 2013). Indeed, the complex nature of sustainability itself explains some of the disagreements over the types of leadership necessary to the successful implementation of SD in organizations. Added to the challenges associated with complex problem solving and the complexity of leadership itself, these challenges can become overwhelming.

Complex leadership theory (CLT) provides guidelines to bridge the notions of complexity and the corresponding requirements for leaders. With this goal in mind, UhlBien, Marion \& McKelvey (2007) provide a framework to guide leaders so they can 
interact with the administrative structure of organizations, coordinate complex dynamics and enhance organizations' overall flexibility, a fundamental SD requirement (Uhl-Bien et al., 2007).

Seeking organizational outcomes necessary to SD challenges, such as learning, innovation, and adaptability, the goal of complex leadership theory is grounded in creativity and empowerment. It argues for ways to manage three entangled leadership roles to foster the adaptive capacity of organizations. More specifically, it looks at how administrative leadership, adaptive leadership, and enabling leadership can work in harmony with each other and in the spirit of SD.

CLT explains that, on the one hand, there is the need for administrative leadership that combines actions taken by individuals and groups in formal managerial roles. These are responsible for planning and coordinating activities ranging from articulating a vision to outlining organizational strategy within the organization's hierarchy.

On the other hand, we need to encourage the informal emergence of adaptive leadership, either in the boardroom or within workgroups of line workers, a form of leadership that is not an act of authority. As such, it becomes a dynamic of interdependent members instead of an individual acting alone. Adaptive leadership occurs in the "struggles between agents and groups over conflicting needs, ideas, or preferences; it results in movements, alliances of people, ideas, or technologies, and cooperative efforts" (UhlBien et al., 2007, p. 306).

CLT's main contribution is with the third and final form of leadership, one that enables adaptive leadership to thrive. Labelled as enabling leadership, it looks to merge tensions between administrative leadership and adaptive leadership in order to enhance the effectiveness and flexibility of organizations. Perhaps the most valuable approach for organizations struggling with progress towards increased social and environmental responsibility will be to enable the participation of emergent leaders, individuals who informally emerge as leaders and who can exert influence by gaining support from other group members (Metcalf \& Benn, 2013).

Given that complexity leadership occurs in the face of adaptive challenges, this perspective conceptualizes leadership as a force that occurs within organizational members as opposed to one that comes from managerial positions, a view that is consistent with the idea of shared leadership (Metcalf \& Benn, 2013; Uhl-Bien et al., 2007).

Indeed, the potential benefits of involving employees from multiple levels to collaborate on SD efforts can yield some positive effects in terms of tackling complexity and in terms of organizational human resources strategy. This approach not only holds the potential to enhance the quality of candidates recruited, it is likely to increase employee motivation levels; and improve retention rates (Hodgman, 2017). In fact, it has been observed that increased participation results in higher happiness levels (Hodgman, 2017). Our educational challenge then becomes to train future leaders to be open to multidisciplinary ideas and to listen to- and motivate- their workforce to participate in SD efforts.

\section{A Focus on Combining Multiple Voices}

We have shown that the complexity of the SD challenge for organizations means that a potential solution may be that of complexity leadership from those who 
enable the future rather than direct it, those who use language to create shared meaning from conflict, who create conditions for individuals to be innovative and learn as a group (Metcalf \& Benn, 2013).

When reflecting on who will take the leadership responsibility for making things right and lead us into a more sustainable future, it seems unlikely that a leader alone will have sufficient information to develop solutions for the organization (Ferdig, 2007; Uhl-Bien et al., 2007). Perhaps what leaders require is training in is finding ways to enable higher levels of participation from organizational members in a form of 'shared leadership' where leaders encourage their followers to engage in SD leadership behaviours (Metcalf \& Benn, 2013). Individuals throughout the organizations should be encouraged and empowered to improve ecological innovation and find new "green" alternatives to wasteful products and processes (Starik \& Rands, 1995).

In addition to developing a deep and widespread commitment to SD among organizational members, we might benefit from collaborating with various experts. Perhaps the greatest lesson we can borrow from biomimicry is the call for combining specialists from multiple fields of studies in order to enhance holistic learning.

Allenby (2011) claims that we have neglected to combine multidisciplinary perspectives, not only in our search for understanding climate change, but also in our efforts to disseminate information about said findings. Consequently, we have not been able to identify appropriate SD solutions. In short, a more holistic approach to understanding the complexity of the sustainability problem requires close collaboration between the physical and social sciences Allenby (1999; 2009; 2011).

Corporate leaders have been immersed in scientific knowledge describing the ecological crisis but perhaps information from the natural sciences is not enough. The field of strategic thinking favours the combination of social scientific theoretical and conceptual work with that of the natural sciences for optimal metrics and scientific measuring (Baumgartner \& Korhonen, 2010).

The call for a multidisciplinary approach, not only for improved understanding of sustainability problems; but also in terms of improving how we communicate findings and discover corresponding solutions, might be the change with need for leadership and SD. Schein (2015) began that process in the classroom by combining business and environmental studies students in his classes. The rationale behind this choice was to inform discussions about sustainability from different perspectives.

The ultimate interdisciplinary ideal would be to combine experts from multiple professions around decision boards. By joining forces, the physical, natural, and social sciences can potentially delve deeper into the complexity of issues do justice to their scope. Leadership for SD appears to rest in part on the shoulders of a synergistic research and academic community.

\section{Conclusion}

We believe that the next major paradigm shift that is needed in the business curriculum is one related to sustainable development. As discussed in this paper, we argue that educators must create a curriculum that encourages students to reflect upon the worldviews that guide business strategy and emphasizes the significant benefits of 
sustaincentricsm for sustainable development. Furthermore, future leaders have to be provided with the tools that enable them to carry out competitive strategies grounded in SD practices.

We have also discussed how leadership for sustainability doesn't only depend on leaders of extraordinary abilities but is also contingent on combining the voices of many collaborators, both within the organization and beyond, thereby benefitting from those from multiple fields of expertise.

Given that the types of leaders who are going to successfully take on SD challenges are those who can read and predict within a context of complexity, think through complex problems, and engage their teams in dynamic adaptive organizational change (Metcalf \& Benn, 2013), then as educators we must integrate this content within our curriculum so that this form of leadership can be fostered in the classroom.

\section{References}

Allenby, B (1999). Culture and Industrial Ecology. Journal of Industrial Ecology.

Allenby, B (2009). The Industrial Ecology of Emerging Technologies. Journal of Industrial Ecology.

Allenby, B. (2011). Thoughts on Industrial Ecology, Emerging Technologies, and Sustainable Science. Integrated Research Systems for Sustainability Science, 6, 119-122.

Baumgartner, R. J. \& Korhonen, J. (2010). Strategic Thinking for Sustainable Development. International Sustainable Development Research Society, Vol ?

Benyus, J. M. (2002). Biomimicry: Innovations Inspired by Nature. New York, NY: Morrow.

Delios, A. (2005). How can organizations be competitive but dare to care? Academy of Management Perspectives, 24(3), 25-36.

DeLuca, D. (2012a). Ecological thinking for radical transformation. BCI: Biomimicry for Creative Innovation. http://businessinspiredbynature.com/wp-content/uploads/2013/02/EcologicalThinking-for-Radical-Transformation.pdf. Accessed 11 June 2013.

DeLuca, D. (2012b). Leadership inspired by nature. BCI: Biomimicry for Creative Innovation. http://businessinspiredbynature.com/wp-content/uploads/2013/02/Leadership-Inspired-byNature.pdf. Accessed 11 June 2013.

Ferdig, M. (2007). Sustainable leadership: Co-creating a sustainable future. Journal of Change Management, 7(1), $25-35$.

Gladwin,T. N., Kennelly, J. J., \& Krause, T-S. (1995). Sustainable paradigms for sustainable development: Implications for management theory and research. Academy of Management Review. 20(4), 874-907.

Hanna, M. (1995). Environmentally Responsible Managerial Behavior: Is Ecocentrism a Prerequisite? Academy of Management Review, 20(4), 796-799.

Hodgman, K. L. (2006). The Sustainability Analysis Framework: An Effective Communication Tool in a Whole of Government Context, Systems, Cybernetics and Information, 5(3), 64-69.

Kennedy, E., Fecheyr-Lippens, D., Hsiung, B., Niewiarowski, P., \& Kolodziej, M. (2015). Biomimcry: A path to sustainable innovation. Design Issues, 31(3), 66-73.

Lertpratchya, A. P., Besley, J. C., Takahashi, B. Zwickle, A \& Whitley, C. T. (2017). Assessing the role of college as a sustainability communication channel, International Journal of Sustainability in Higher Education, Vol?

Metcalf, L. \& Benn, S. (2013). Leadership for sustainability: An evolution of leadership ability. Journal of Business Ethics, 112(3), 369-384.

Roome, N. (2001). Conceptualizing and studying the contribution of networks in environmental management and sustainable development, Business Strategy and the Environment Editorial, 10, 69-76.

Shrivastava, P. (1995). The role of corporations in achieving ecological sustainability. Academy of Management Review. 20(4), 936-960.

Starik, M. \& Rands, G. P. (1995). Weaving an integrated multilevel and multi system perspectives of ecologically sustainable organizations. Academy of Management Review. 20(4). 908-935. 
Schein, S. (2015). A new psychology for sustainability leadership. Sheffield, UK: Greenleaf Publishing Ltd

Stubbs, W. \& Cocklin, C. (2008). Teaching sustainability to business students: Shifting mindsets. International Journal of Sustainability in Higher Education. 9(3), 206-221.

Uhl-Bien, M, Marion, R., McKelvey, B. (2007). Complexity leadership theory: Shifting leadership from the industrial age to the knowledge era. The Leadership Quarterly. 18 0.298-318.

Weilkiewicz, R. M. \& Stelzner, S. P. (2010). An ecological perspective on leadership theory, research, and practice. Review of General Psychology, 9(4), 326-341. 